\title{
sciendo
}

\section{Does the Degree of Urbanisation Affect Sustainable Household Consumption? (Some Empirical Evidence)}

\author{
Todor KRASTEVICH \\ D. A Tsenov Academy of Economics, Svishtov, Bulgaria \\ t.krastevich@uni-svishtov.bg \\ Marusya SMOKOVA \\ D. A Tsenov Academy of Economics, Svishtov, Bulgaria \\ m.smokova@uni-svishtov.bg
}

\begin{abstract}
This paper is aimed at identifying the factors that shape consumers' interest and propensity for sustainable consumption. It is focused on the differentiation of households in regard to their stated willingness to comply with the principles of sustainable consumption, as well as the identification of differences in the forms of manifestation of sustainable consumer behaviour among the households from different-sized urban areas. To achieve these objectives, first, we have evaluated a second-order factor model of CSC. We have also proposed a CSC Index model at an individual level. Second, we have conducted cluster analysis using the factor scores of the CSC Index model while considering households' socio-demographics and the size of the urban area. We have identified two segments, 'Sustainable conscious' versus 'Sustainable unconscious'. Finally, we have identified the environmental dimension as the most significant predictor of consciousness for sustainable consumption using a path model of CSC Index.
\end{abstract}

Keywords: sustainable consumption, conscious consumer behaviour, consciousness for sustainable consumption index, structural equation modelling, clustering

Please cite the article as follows: Krastevich, T. and Smokova, M. (2021), "Does the Degree of Urbanisation Affect Sustainable Household Consumption? (Some Empirical Evidence)",

Management \& Marketing. Challenges for the Knowledge Society, Vol. 16, No. 3, pp. 187-209, DOI: 10.2478/mmcks-2021-0012.

\section{Introduction}

In general, the concept of sustainable consumer behaviour refers to the behaviour in which users fully or predominantly prefer consuming sustainable substitutes. By sustainable substitutes, we mean everything related to the life cycle of consumption from pre-acquisition (raw materials, production and delivery of products and services that are necessary for consumption), the acquisition itself (purchase, possession and use), to recycling and disposal. Sustainable consumer behaviour is also associated with all the accompanying responsible actions that can benefit the environment and are crucial for a healthy and sustainable lifestyle in society. Thus, sustainable consumer behaviour does not only ensure prosperity in the present, but sustainable well-being for future generations.

Unfortunately, there is no common understanding of what sustainable consumption actually means in marketing and consumer research. Usually, sustainable consumption is perceived as purchase and use of environmentally friendly products. 
However, this notion is too narrow, as consumer consumption sustainability involves various forms of manifestation, including purchases of environmentally friendly products, fair trade products, orientation towards shared consumption of products, as well as following a more modest and less materialistic consumption lifestyle.

In this paper, our presumption is that sustainable consumer behaviour occurs in sustainable consumer consumption, and therefore we will avoid distinguishing between these two concepts. Furthermore, we perceive 'responsible consumer behaviour' and 'sustainable consumer behaviour' as analogous concepts. In addition, the concept of 'responsible' includes the moral (not legal) responsibility to the society, environment (in particular, the ecological environment) and future generations.

The objectives of this paper are: (1) to discover and systematise new theoretical and empirical knowledge about the factors that shape consumers' interest and propensity for sustainable consumption; (2) to identify heterogeneity between consumers regarding their stated willingness to comply with the principles of sustainable consumption, as well as (3) to identify differences in the forms of manifestation of sustainable consumer behaviour between the households from different-sized urban areas.

\section{Literature Review and Prior Research}

Almost 50 years have passed since John Fisk debated the theory of responsible consumption in the 70s, but today his rationale for economic development, viewed from three different perspectives, is even more relevant, namely: (1) the ecological viewpoint (concern about human survival); (2) views on the growth of neo-Malthusian (thesis: an increase in the standard of living is directly related to a decrease in the birth rate and the preservation of natural resources) and neo-Luddite (thesis: modern computer technologies and artificial intelligence are perceived as a threat to people, and for their jobs, respectively); and (3) the economic development viewpoint (thesis: environmental pollution comes from the perverse system of incentives for industry, not from growth). Even then, Fisk postulated that „marketing managers can use the theory of responsible consumption as a guide to marketing policy, even if they do not have social performance indicators with which they can adapt to their operating environment" (Fisk, 1973, pp. 28-29).

In the 70s, socially responsible behaviour and consumption became a research interest for a number of authors. Some of them (Anderson and Cunningham, 1972) have developed the personal sociopsychological construct of "socially conscious behaviour" and applied it as a basis for market segmentation. Others (Webb et al., 2008; Webster, 1975) have attempted to design and empirically test scales and indices for measuring the "socially responsible behaviour" using indicators of attitudes, personal characteristics and social activity of users. Thereafter, the scales and indices of socially responsible behaviour have been used to identify and profile the segment of the socially responsible user (Antil, 1984; Antil and Bennett, 1979; Roberts, 1995). At the same time, the efforts of some authors (Kircova et al., 2016) have been focused on the definition of factors that influence socially responsible consumption, generally, and in relation to specific product categories (Ha-Brookshire and Hodges, 2009). In more recent years, some researchers (Francois-Lecompte and Roberts, 2006; Pérez-Barea et al., 2018) have attempted to design indices of the socially responsible behaviour by implementing factor analysis. Unfortunately, none of them are generally accepted.

In the 1990s, Schwepker and Cornwell (1991) developed a scale for measuring attitudes and buying intentions of the so-called 'environmentally concerned' consumers 
based on their sociopsychological and demographic characteristics. This period has also been marked by Roberts and Bacon's (Roberts and Bacon, 1997) prominent research on the links between environmental issues and environmental conscious consumer behaviour. Later, Kaiser et al. (Kaiser, Ranney, et al., 1999; Kaiser, Wölfing, et al., 1999) defined the term 'ecological' behaviour as a function of the knowledge about the environment, a sense of personal and collective responsibility, and shared values. At the same time, Follows and Jobber's (Follows and Jobber, 2000) published their attempts to design and empirically test models of environmentally responsible buying behaviour. It is noteworthy to highlight that these prominent research efforts were made during a period in which researchers relied mainly on the structural equation modelling for measuring the environmentally responsible buying behaviour. Previous research was mainly based on the application of exploratory and confirmatory factor analysis and/or reliability analysis.

According to Gupta and Singh (Gupta and Singh, 2020, pp. 130-131), sustainable consumer behaviour occurs (and could be empirically studied, respectively) in the following areas:

- Responsible purchasing - considers the purchase of goods and the use of services that do not harm the environment, as well as the behaviour that leads to the purchases of such products.

- Responsible usage - refers to sustainable and responsible ways of consuming, as the use behaviour affects the environment in terms of the ways and habits of using the purchased products, and resources, respectively.

- Responsible maintenance - refers to the maintenance of purchased and used products in good conditions through regular inspections and repairs, in order to extend the life of the product.

- Responsible disposal - covers disposal (if possible, recycling), as well as the activities of consumers after the disposal of the product. This area is important because it covers activities for the proper treatment of household waste and waste from activities outside the home.

- Responsible social activity - includes consumer relations and activities related to supporting petitions, joining environmental organisations, supporting public policies, environmental discussions, donations for environmental conservation and/or recycling, etc.

For consumers, all the above-mentioned areas mean that there are different ways to consume 'sustainably'. For companies, they mean that it is necessary to identify and profile the market segment of the sustainable consumer (Balderjahn and Hüttel, 2019a). A very intuitive, though elementary approach for market segmentation analysis, is to search for a priori differences between the customers/households depending on the specificities and regional differences in consumption in the urban environment.

In this study we start from the hypothesis that sustainable consumption can best be characterised as a multidimensional latent construct and its empirical analysis could be used as a useful basis for planning effective market segmentation strategies and selection, comparison, and application of relevant marketing tools. We believe that knowing the causes and consequences of conscious sustainable consumer behaviour is a prerequisite for implementing successful marketing strategies and practices of sustainable consumption.

Following these assumptions, we have extended and verified the tricomponent model of consciousness for sustainable consumption (CSC), which was proposed, designed and further upgraded by Balderjahn et al. (Balderjahn, Buerke, et al., 2013a; 
Balderjahn et al., 2018a, 2019; Balderjahn, Peyer, et al., 2013; Balderjahn and Hüttel, 2019b; Balderjahn and Peyer, 2012). The model includes environmental, social and economic dimensions of sustainable consumption consciousness and their impact on various aspects of consumer behaviour. We have evaluated the capabilities of our CSC model in predicting sustainable consumption behaviour and tried to determine whether the environmental, social, and economic dimensions of sustainable consumption in different urban settings depend on consumer awareness and consumers' shared human values, and how they impact the conscious consumer behaviour.

\section{Measuring conscious sustainable consumer consumption Conceptual framework}

Sustainable patterns of consumer behaviour recreate conscious consumption, which "...is guided and underpinned by a mindful mindset that reflects a conscious sense of caring toward self, community, and nature" (Sheth et al., 2011, p. 27). The consciousness of sustainable consumption is defined as the intention to consume in a way that enhances the environmental, social, and economic aspects of the quality of life (Balderjahn, Buerke, et al., 2013b, p. 182). The consciousness of sustainable consumption involves the creation and observance of reasonable habits in the purchase, use and disposal of products, as well as the use of services, in which people consider the consequences of consumption for: (1) the environment (the environmental dimension that reflects, for example, care for the environment, as well as the protection and gentle use of natural resources with care for future generations); (2) community (a social dimension that reflects, for example, the role of social networks and movements, attitudes towards public goods); and (3) well-being (an economic dimension described as a conscious sense of concern for long-term economic and personal well-being). Sustainable consumption refers to the act of consciously avoiding over-buying and judiciously using goods and services that meet the basic needs of the individuals and households (Quoquab et al., 2019, p. 769). Following the results of Balderjahn's research, our initial conceptual framework for measuring conscious sustainable consumer consumption fits into the following verbal structure:

Table 1. Initial conceptual framework of the research

\section{Consciousness for Sustainable Consumption (CSC)*}

\begin{tabular}{lll}
\hline $\begin{array}{l}\text { Environmentally friendly } \\
\text { consumption (ENV) }\end{array}$ & $\begin{array}{l}\text { Socially fair consumption } \\
\text { (SOC) }\end{array}$ & $\begin{array}{l}\text { Economically reasonable } \\
\text { consumption (ECON) }\end{array}$ \\
\hline - Disposal environmentally friendly & - Human rights & - Sparing consumption \\
- Packaging & $\begin{array}{l}\text { - Social minimum standards } \\
\text { - Non-violence on workers }\end{array}$ & - Reduced amount of electricity \\
- Recycling & - Fair compensation & usage \\
- Ecological technology & & - Reduced amount of water usage \\
- Environmentally harmless & & - Ling time usage \\
ingredients and substances & & - No debt-burdens \\
& & - Financial reserve for emergency \\
& & - Financial stability \\
& & - Safeguarding for future \\
& & - Utilitarian and/or hedonistic \\
& & consumption \\
& & - Do not buy more than needed \\
& - Buy things they are really useful \\
& & - Really like and want to own \\
& - Everyone else already owns them \\
\hline
\end{tabular}


In our research, we have expanded and adapted the above-mentioned research framework by considering country- and region-specific indicators.

\section{Operational framework}

The consciousness for sustainable consumption $\left(C S C_{i}\right)$ of consumer $i$ refers to socially and environmentally awareness and concerned way of buying, using and disposing of goods and services. It implies the understanding of quality of life by following a reasonable and careful model of consumption, as well as an efficient use of goods and services. The consciousness of sustainable consumption does not contradict the desire to meet the basic needs of the current users. It implicitly protects the needs of the future generations at the same time.

We assume that sustainable consumption consciousness is a multidimensional construct that can be operationalised as follows (Balderjahn, Buerke, et al., 2013a, p. 184):

$$
\operatorname{CSC}_{(i)}=\{E N V ; S O C ; E C O N\}=\left\{\sum_{j_{1}=1}^{J_{1}} B_{i j} \times I_{i j} ; \sum_{j_{2}=1}^{J_{2}} B_{i j} \times I_{i j} ; \sum_{j_{3}=1}^{J_{3}} B_{i j} \times I_{i j}\right\},
$$

where $B_{i j}$ is the belief of consumer $i$ about sustainable product attributes or consequences $j$ (with $j=1, \ldots J$ ). $I_{i j}$ is the importance that consumer $i$ assigns to the relevant attributes or consequences $j$ associated with sustainable consumption. The criteria for sustainable consumption $J$, identified by Balderjahn, are divided into three separate subgroups - ecological $J_{E N V}$, social $J_{S O C}$, and economic $J_{E C O N}$.

To confirm the validity and reliability of the scale 'sustainable consumption consciousness', it is necessary to define a set of indicators for measuring each of the three subgroups of criteria and evaluate these indicators using a survey of respondents (households). We have applied a biased cluster sampling procedure, which allowed us to identify possible differences in sustainable household consumption in different urban settings (capital city, large city and small city). We have calculated the score of $\operatorname{CSC}_{i}$ for each respondent $i$ using the above-mentioned formula. The estimated scores of $\operatorname{CSC}_{i}$ allowed us to check if there are statistically significant differences among users in the observed urban areas and whether they are related to the degree, size and specification of urbanisation. Our survey questionnaire also included some sociodemographic variables (e.g. gender, age, household size, educational level, net monthly expenses, etc.), which have been used for household segmentation and profiling in each of the analysed urban areas.

\section{Scale development and refinement}

We have assumed that consciousness for environmental consumption, consciousness for social consumption and consciousness for economic consumption are unobservable hypothetical psychological constructs, which make up the composite structure of consciousness for sustainable consumption. Thus, the latter should be measured by a set of observable indicators. Due to the complexity of the economic dimension, we have assumed that it is composed by three sub-dimensions - striving for voluntary simplicity, striving for debt-free consumption, and striving for self-restraint consumption. Our hypothesis was grounded on the results of previous research (Balderjahn, Buerke, et al., 2013a; Balderjahn et al., 2018b), which have been modified and extended after considering the insights gained from focus groups and expert interviews. We have conducted three focus groups and defined an initial extended list of possible indicator statements. After a field pretesting of the questionnaire with a sample of 85 typical representatives of the target population in the observed cities, we have made several 
adjustments and improvements and come to our final list of candidates (Table 3) for indicator variables for each the three dimensions of the consciousness for sustainable consumption.

\section{Samples description and data screening}

We have used a biased cluster sampling procedure. The sample comprised of 1049 households with a permanent residence in three different-sized urban areas - capital city of Bulgaria (Sofia, ca. 1,263K residents, ca. 573K households), a large industrial port city on the Black Sea coast (Varna, ca. 335K residents, ca. 195K households), and a relatively small provincial city on the banks of the Danube River (Svishtov, ca 25K residents, $13 \mathrm{~K}$ households). The respondents (head or representative of the household aged 18+) have been recruited from across the three observed cities by considering the sociodemographic quotas in the locality. The field work was done from February 7 , 2021 to April 21, 2021 through CAPI/CAMI.

As our research requires assessments of latent variables at individual level for follow-up analyses and prediction-oriented segmentation, we have applied a compositebased approach to structural equation modelling with partial least squares algorithm (PLS-SEM). The application of this approach allowed us to evaluate the out-of-sample predictions and use the composite scores (e.g., CSC Index) for further analyses. It also has greater flexibility, because the identification of the model is less constrained (Ghasemy et al., 2020, p. 1123; Hair, Sarstedt, et al., 2019).

First, we have performed data screening by calculating Little's missing completely at random (MCAR) test (Little, 1988). The latter tests a hypothesis that the observed data are missing completely at random (Brown, 2015, p. 334), which is an assumption that must be satisfied before replacing missing values using various imputation techniques. The empirical value of Little's MCAR test confirms that the missing values were completely at random. This allowed us to undertake missing values imputation procedure with MCMC algorithm with logistic regression for categorical variables to impute incomplete variables (IBM Corporation, n.d.).

Table 2. Description of the sample per observed city

\begin{tabular}{|c|c|c|c|c|}
\hline & & \multicolumn{3}{|c|}{ Observed urban area $(n=1049)$} \\
\hline & & $\begin{array}{c}\text { Sofia (Capital city, } \\
\text { residents } \approx 1,236 \mathrm{~K}, \\
\text { households } \approx 573 \mathrm{~K} \text { ), } \\
\mathrm{n}=403 \\
\end{array}$ & $\begin{array}{c}\text { Varna (Large city, } \\
\text { residents } \approx 335 \mathrm{~K}, \\
\text { households } \approx 195 \mathrm{~K} \text { ), } \\
\mathrm{n}=342 \\
\end{array}$ & $\begin{array}{c}\text { Svishtov (Small city, } \\
\text { residents } \approx 25 \mathrm{~K}, \\
\text { households } \approx 13 \mathrm{~K} \text { ) } \\
\mathrm{n}=304 \\
\end{array}$ \\
\hline & & Column N \% & Column N \% & Column N \% \\
\hline \multicolumn{2}{|c|}{ Age group of household $<25$} & $7.4 \%$ & $7.6 \%$ & $15.1 \%$ \\
\hline \multirow[t]{4}{*}{ head (years) } & 25 to 34 & $21.3 \%$ & $19.9 \%$ & $14.1 \%$ \\
\hline & 35 to 49 & $28.5 \%$ & $31.3 \%$ & $30.3 \%$ \\
\hline & 50 to 65 & $27.5 \%$ & $24.6 \%$ & $24.7 \%$ \\
\hline & $>65$ & $15.1 \%$ & $16.7 \%$ & $15.8 \%$ \\
\hline \multirow{5}{*}{$\begin{array}{l}\text { Number of persons in a } \\
\text { household }\end{array}$} & 1 & $33.5 \%$ & $13.5 \%$ & $28.9 \%$ \\
\hline & 2 & $29.5 \%$ & $30.1 \%$ & $25.7 \%$ \\
\hline & 3 & $19.4 \%$ & $27.2 \%$ & $21.1 \%$ \\
\hline & 4 & $13.6 \%$ & $23.4 \%$ & $16.1 \%$ \\
\hline & More than 4 & $4.0 \%$ & $5.8 \%$ & $8.2 \%$ \\
\hline \multirow{6}{*}{$\begin{array}{l}\text { Gender of household } \\
\text { head } \\
\text { Highest educational } \\
\text { level of household head }\end{array}$} & Male & $66.0 \%$ & $75.7 \%$ & $66.8 \%$ \\
\hline & Female & $34.0 \%$ & $24.3 \%$ & $33.2 \%$ \\
\hline & Elementary or lower & $0.5 \%$ & $2.3 \%$ & $1.0 \%$ \\
\hline & education & & & \\
\hline & Secondary education & $26.1 \%$ & $43.6 \%$ & $44.4 \%$ \\
\hline & $\begin{array}{l}\text { Higher education } \\
\text { (Bachelor or Master) }\end{array}$ & $71.5 \%$ & $52.6 \%$ & $52.0 \%$ \\
\hline
\end{tabular}




\begin{tabular}{|c|c|c|c|c|}
\hline & $\begin{array}{l}\text { Academic degree } \\
\text { (PhD) }\end{array}$ & $2.0 \%$ & $1.5 \%$ & $2.6 \%$ \\
\hline \multirow{4}{*}{$\begin{array}{l}\text { Type of household's } \\
\text { primary residence }\end{array}$} & Separate house & $7.7 \%$ & $12.3 \%$ & $17.4 \%$ \\
\hline & House floor & $6.5 \%$ & $9.6 \%$ & $13.8 \%$ \\
\hline & Apartment & $83.1 \%$ & $77.8 \%$ & $66.4 \%$ \\
\hline & Something else & $2.7 \%$ & $0.3 \%$ & $2.3 \%$ \\
\hline \multirow{4}{*}{$\begin{array}{l}\text { Ownership of the main } \\
\text { housing occupied by the } \\
\text { household }\end{array}$} & Own property & $54.6 \%$ & $65.5 \%$ & $63.2 \%$ \\
\hline & $\begin{array}{l}\text { Property owned by } \\
\text { parents or relatives } \\
\text { (no rental) }\end{array}$ & $13.2 \%$ & $17.8 \%$ & $23.0 \%$ \\
\hline & Rental property & $27.3 \%$ & $15.8 \%$ & $11.5 \%$ \\
\hline & No answer & $5.0 \%$ & $0.9 \%$ & $2.3 \%$ \\
\hline
\end{tabular}

Structural equation modelling generally requires large data samples to provide reasonable and reliable estimates of the model parameters. According to Wolf, Harrington, Clark and Miller (Wolf et al., 2013), 10 cases per variable (Nunnally and Bernstein, 1994) or at least 10 observations per estimated parameter (Bentler and Chou, 1987, p. 91) are not sufficient. These rules-of-thumb do not fit for all situations and the sample size estimates may vary. However, a larger data sample (more than 500) is recommended (Yurdugül, 2008), especially when the distribution of observed variables is not normal and if subsequent group analysis of the results is required. In our study, at desired anticipated effect size of 0.15 and statistical power of 0.8 , we have calculated that the minimum sample size to detect an effect was 742 observations (Soper, 2021). After removing the outliers, based on the Mahalanobis distance measure, our sample has been reduced to 1011 observations, which was more than required.

Our confirmatory factor analysis (CFA) model includes 17 observed variables. As we initially intended to use maximum likelihood estimation for CFA, we have checked if the requirement for multivariate normality was satisfied. We used tests for normality and an outlier detection procedure in IBM SPSS AMOS (Arbuckle, 2020). We have found that critical ratio of multivariate kurtosis does not meet the tolerable threshold of 5 (Byrne, 2016, p. 104), which implies that the assumption is not met. Following the procedures of Korkmaz et. al. (2014), we have also performed three alternative tests for multivariate normality (Mardia's test, Henze-Zirkler's test, Royston's test, and DoornikHansen's test). All of them have failed to confirm the hypothesis of a multivariate normal distribution of the data. After identifying and deleting multivariate outliers using the Mahalanobis distance test (Kline, 2015, p. 73), the sample size was reduced to 1000 , which is more than enough for subsequent analysis, but the assumption of multivariate normality was still violated. It was quite clear that the variables in our analysis reflect a significant departure from multivariate normality. Multivariate nonnormality may lead to an inflation in the value of the Chi-square test and an incorrect rejection of a good model.

We have applied a bootstrapping method to correct for the bias associated with parametric extraction of non-normal data (Diaconis and Efron, 1983; Efron, 1982, chap. 5) and avoid any subsequent problems with inflated Chi-square test values, underestimated standard errors, model misspecification, and incorrect inferences of the model parameters (e.g, path coefficients, covariances among factors or residuals). We have chosen bootstrapping procedures over the asymptotically distribution-free estimation (both are available in AMOS) because the asymptotically distribution-free method will perform very poorly and can yield severely distorted estimated values as the sample size was at the lower limit of acceptability (Byrne, 2016, p. 123). Guided by these considerations, we have performed a bootstrapping procedure for all necessary 
evaluations and assessed the overall model fit using Bollen-Stine corrected p-value (Enders, 2002; Kim and Millsap, 2014).

\section{Specification and identification of the CSC model}

We have extracted from the data set six latent constructs with a meaningful interpretation (Table 3) using explorative factor analysis with principal component method at the preliminary stage. Cronbach's alpha was used to assess the internal consistency of extracted latent constructs. Alpha coefficients of reliability for each construct (except HEDO (Hedonistic consumption)) show a fairly high internal consistency ( $>0.7$ ). We have excluded construct HEDO from the structural model of CSC. Remaining factors explain over $70 \%$ of the cumulative variance and each one has eigenvalue over 1, which agrees with the Kaiser criterion (Braeken and van Assen, 2017; Kaiser, 1960).

Table 3. Results of preliminary exploratory factor analysis

\begin{tabular}{|c|c|c|c|c|}
\hline CSC scale & $\begin{array}{l}\text { B: We buy things if we believe that ... } \\
\quad \times \\
\text { I: How important is it for your household that ... }\end{array}$ & $\begin{array}{r}\text { EFA } \\
\text { factor } \\
\text { loading }\end{array}$ & $\begin{array}{l}\text { Internal } \\
\text { Consistancy } \\
\text { (Cronbach's } \\
\text { Alpha) } \\
\end{array}$ & $\begin{array}{c}\% \text { of } \\
\text { Variance } \\
\text { extracted }\end{array}$ \\
\hline \multicolumn{5}{|c|}{ Constructs /items } \\
\hline ENV (Env & ironmentally friendly consumption) & & 0.897 & 32.419 \\
\hline Env1 & ... they can be disposed of in an environmentally friendly manner & 0.821 & & \\
\hline Env2 & ... their packaging can be recycled & 0.846 & & \\
\hline Env3 & ... they are made of recyclable materials & 0.814 & & \\
\hline Env4 & ... they are made according to ecological technologies & 0.839 & & \\
\hline Env5 & ... they don't contain any environmentally harmful ingredients and/or substances & 0.740 & & \\
\hline DEBT (De & ebt-free consumption) & & 0.886 & 15.735 \\
\hline Debt1 & ... we don't have to take money from our financial reserve for emergency cases for it & 0.826 & & \\
\hline Debt2 & ... the expenses don't unduly burden our financial situation & 0.811 & & \\
\hline Debt3 & ... we don't become overindebted in the long term & 0.815 & & \\
\hline Debt4 & ... we don't have to forego future purchases & 0.799 & & \\
\hline SOC (Soci & ally fair consumption) & & 0.936 & 9.208 \\
\hline Soc1 & ... the workers are not abused in their production & 0.900 & & \\
\hline Soc2 & ... they are produced by workers who are treated fairly or are fairly compensated & 0.889 & & \\
\hline Soc3 & ... the workers' human rights are adhered to in their production & 0.913 & & \\
\hline SPAR (Sp & aring consumption) & & 0.798 & 6.850 \\
\hline Spar1 & ... this will reduce the amount of electricity used & 0.863 & & \\
\hline Spar2 & ... this will reduce the amount of water used & 0.859 & & \\
\hline Spar3 & ... we will be able to use them for a long time & 0.509 & & \\
\hline UTIL (Uti & litarian consumption) & & 0.708 & 5.981 \\
\hline Util1 & ... we don't buy more than we need at the moment & 0.837 & & \\
\hline Util2 & ... they are really useful & 0.739 & & \\
\hline HEDO* $(\mathrm{H}$ & Iedonistic consumption) & & $0.412 *$ & 4.109 \\
\hline Hed1 & ... everyone else already owns them & 0.821 & & \\
\hline Hed2 & ... we really like them and want to own them & 0.725 & & \\
\hline
\end{tabular}

Next, we have proved how the items are ordered within the constructs using their factor loadings. Using confirmatory factor analysis, we have tested whether items of extracted constructs were consistent with our understanding of the nature of hypothetical dimensions. We have used a second-order CFA to test the assumption that the relationships among the set of first-order factors that reflect the consumption reflect the same dimension of sustainable household consumption. Following Brown's approach for developing and testing a second-order factor model (Brown, 2015, p. 290), we have developed a conceptually valid first-order CFA model (Figure 1, left part), comprised of five latent constructs identified through factor analysis - environmentally friendly consumption (ENV), debt-free consumption (DEBT), socially fair consumption (SOC), sparing consumption (SPAR), and utilitarian consumption (UTIL). We have evaluated the correlations among the first-order factors to determinate if it is 
reasonable to compose a second-order factor, which is able to produce associations among the first-order factors. Pattern and structure coefficients indicate strong relationships between the first-order factors and their indicators. The correlations between DEBT, SPAR, and UTIL are relatively strong $\left(r_{i j}>0.5\right)$, while the correlations between these three factors and the other two (ENV and SOC) are relatively low $\left(r_{i j}<\right.$ $0.5)$. The pattern of correlations suggests that one second-order factor may explain the correlation between DEBT, SPAR, and UTIL. Logically, we have called this factor `economically reasonable consumption` (ECON).

First-order CFA

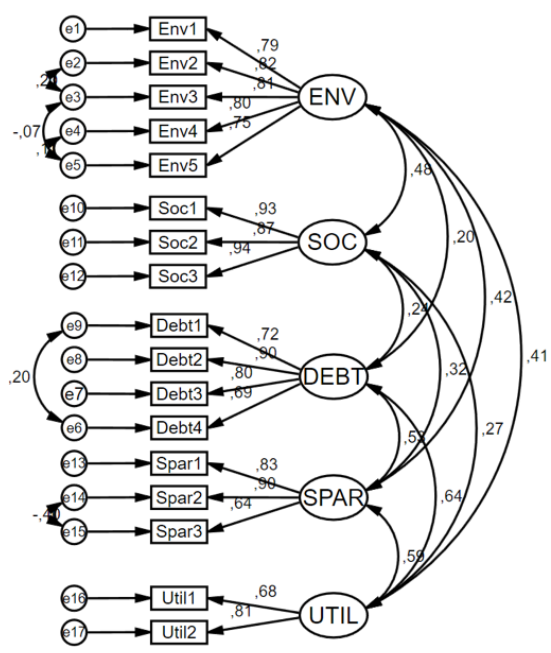

Fit indexes:

Chi square $(\mathrm{CMIN})=350.745(\mathrm{df}=104)$

$\mathrm{CMIN} / \mathrm{df}=3,373$

Bollen-Stine corrected $\mathrm{p}$-value $=0.002$

AGFI $=0.946$

$\mathrm{CFI}=0.977$

$\mathrm{GFI}=0.963$

RMSEA $=0.048$

\section{Second-order CFA}

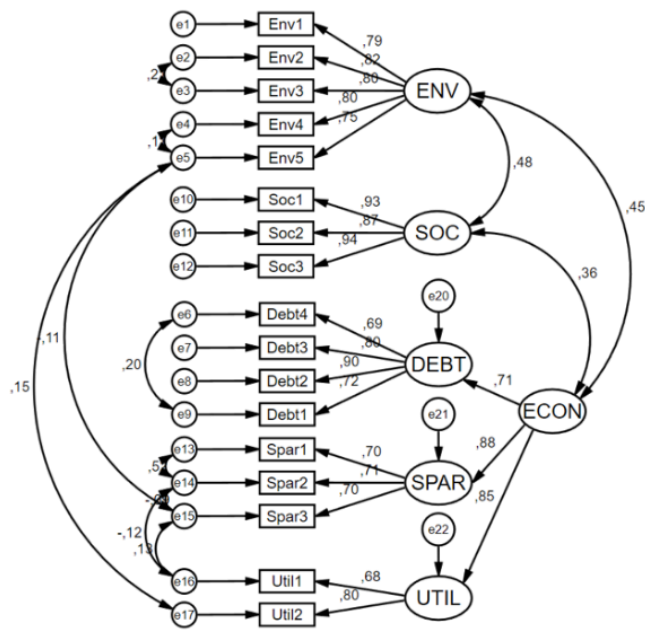

Fit indexes:

(1) Chi square $($ CMIN $)=292.590(\mathrm{df}=104)$ $\mathrm{CMIN} / \mathrm{df}=2.813$

Bollen-Stine corrected p-value $=0.002$ AGFI $=0.953$

$\mathrm{CFI}=0.982$

$\mathrm{GFI}=0.968$

RMSEA $=0.042$

Figure 1. First- and second-order CFA for CSC scale development

Source: Authors' own research

The proposed second-order factor model (Figure 1, right part) includes five firstorder factors and one second-order factor. The second-order factor ECON is composed to account for the correlation between the first-order factors DEBT, SPAR, and UTIL. The standardized loadings in the model are the correlations between the indicator variables and the latent factors. The double-headed arrows among the latent factors represent correlations. The double-headed arrows between error terms represent correlations among the errors. The correlation between ENV and ECON is $r=0.45$, whereas the correlation between ENV and SOC is $r=0.48$. The correlation between SOC and ECON is $r=0.36$.

The model fits very well to the data (Table 3). Using the modification indices approach (Arbuckle, 2020), theoretical consideration, and common sense, we have added several additional parameters, which significantly improved the goodness-of-fit of our model. The traditional approach for testing a model for goodness of fit is the Chisquare test. It is used to evaluate whether a model departs significantly from one that fits exactly to the data. Traditionally, if $\mathrm{p} \leq 0.05$, then we reject the null of an exact-fitting model. Technically, the p-value should be greater than 0.05 , i.e., statistically insignificant. However, in practice the p-value is very sensitive to the sample size and 
frequently results in rejection of a well-fitting model (Chen and Tsai, 2007, p. 1118). We do not report significance level (Bollen-Stine corrected p-value) of Chi-square (CMIN) in this paper as the role of significance testing in structural equation modelling is much smaller in comparison with the other standard regression based statistical techniques (Kline, 2015, p. 17). One of the reasons is that the view of specific effects represented in the model takes precedence over the entire model. Moreover, the higher the number of sample size, the lower the probability for insignificant $\mathrm{p}$-value of Chi-square test. Due to this limitation of Chi-square test, other model fit indices are more important to check model fit. However, there is still a debate on this issue. According to Barret (2007) "...the Chi-square exact-fit test is the only substantive test of fit for SEM, but, its sensitivity to discrepancies from expected values at increasing sample sizes can be highly problematic if those discrepancies are considered trivial from an explanatorytheory perspective". The ration of Chi-square value and degree of freedom is acceptable. Comparative fit index (CFI=0.982) may be considered as evidence of 'superior fit' (Byrne, 2016, p. 97; Hu and Bentler, 1999). Considered as an 'absolute fit index', the Root mean-squared error of approximation (RMSEA=0,042) is below 0.06. According to Browne and Cudeck (1992, p. 239), it indicates a close fit of the model to the data in relation to the degrees of freedom. Because our sample size is more than 500, we have reported as fit index the Standardized Root Mean Squared Residual (SRMT) as well, which is a measure of the mean absolute covariance residual. According to Kline (2015, p. 277), values of SRMR $>0.10$ may indicate poor fit. In our case, SRMR is 0.045 , which is excellent. We have also reported the results from p-close test. If we assume that an RMSEA value $\leq 0.05$ represents a close-fitting model, then a p-close test value, where $\mathrm{p}>0.05$, can be viewed as supporting the null hypothesis of close model fit. In our case, p-value of PCLOSE test statistics is 0.993, which is definitely much higher than the critical value of 0.05 . This suggests not to reject the null hypothesis of close fit (i.e., it does support our model).

Table 4. Goodness-of-fit of second-order CFA model

\begin{tabular}{llll}
\hline \multicolumn{3}{l}{ Second-order CFA Model Fit Measures } & \\
\hline Measure & Estimate & Threshold & Interpretation \\
\hline CMIN & 292.590 & -- & -- \\
DF & 104.000 & -- & -- \\
CMIN/DF & 2.813 & Btw. 1 and 3 & Acceptable \\
CFI & 0.982 & $>0.95$ & Excellent \\
SRMR & 0.046 & $<0.08$ & Excellent \\
RMSEA & 0.042 & $<0.06$ & Excellent \\
PCLOSE & 0.993 & $>0.05$ & Excellent \\
& & & \\
\hline
\end{tabular}

\begin{tabular}{llll}
\hline \multicolumn{3}{l}{ Cutoff Criteria* } \\
\hline Measure & Terrible & Acceptable & Excellent \\
\hline CMIN/DF & $>5$ & $>3$ & $>1$ \\
CFI & $<0.90$ & $<0.95$ & $>0.95$ \\
SRMR & $>0.10$ & $>0.08$ & $<0.08$ \\
RMSEA & $>0.08$ & $>0.06$ & $<0.06$ \\
PCLOSE & $<0.01$ & $<0.05$ & $>0.05$ \\
\hline *Note: According to Hu and Bentler (1999) and \\
Gaskin and Lim (2016) recommend combinations \\
of measures,
\end{tabular}

Source: Authors' own research

\section{Validation of the CSC model}

As part of the confirmatory factor analysis, we have checked four different types of validities: content validity, convergent validity, discriminant validity, and nomological validity (Homburg and Giering, 1996). Because content validity is determined by the degree to which the variables in a given measurement model belong to the semantic area of the studied construct, and the constructed elements fully reflect all content aspects of the construct, we have not evaluated this explicitly. Convergent validity is explained by the extent to which there are strong associative relationships between the indicator variables describing a latent construct. To estimate the convergent validity, we 
have first calculated average variance extracted test statistic (AVE). AVE is just the average of the squared standardized pattern coefficients for indicators that depend on the same factor, but are specified to measure no other. Recommended values are greater than 0.5 (Kline, 2015, p. 313). In addition, we have assessed internal composite reliability (CR). Our expectations for AVE were to be greater than 0.7 (Fornell and Larcker, 1981). We have also used heterotrait-monotrait ratio of correlations (HTMT) as an alternative to Fornell-Larcker CR criteria of discriminant validity (Henseler et al., 2015), where if HTMT value is below 0.90, discriminant validity has been established between two reflective constructs.

The main indicators for measuring the construct validity of the model are shown in Table 5a and Table 5b. The threshold values for assessing the validity are accepted as suggested by Hu and Bentler (1999) and Gaskin, James, and Lim (2019). HTMT criterion for assessing discriminant validity is based on the prominent work of Henseler, Ringle, and Sarstedt (2015). Thresholds are 0.850 for strict and 0.900 for liberal discriminant validity. It is clear that there are no validity concerns here. All estimates exceed the standard minimum thresholds. The square root of the AVE for all constructs (in bold) are more than one absolute value of the correlation with another factors.

Table 5. Convergent and discriminant validity of second-order CFA model

$$
\text { a. }
$$

a.

\begin{tabular}{|c|c|c|c|c|c|c|c|c|c|c|}
\hline vaticis & $\mathrm{CR}$ & AVE & MSV & $\operatorname{MaxR}(\mathrm{H})$ & ENV & SOC & ECON & ENV & SOC & ECON \\
\hline ENV & 0.894 & 0.628 & 0.227 & 0.896 & 0.793 & & & -- & & \\
\hline SOC & 0.936 & 0.831 & 0.227 & 0.942 & $0.476^{\text {*** }}$ & 0.911 & & 0.480 & -- & \\
\hline ECON & 0.856 & 0.667 & 0.205 & 0.876 & $0.453^{* * *}$ & $0.356^{* * *}$ & 0.817 & 0.386 & 0.330 & -- \\
\hline
\end{tabular}

Significance of Correlations: ${ }^{* * *} \mathrm{p}<0.001$

Source: Authors' own research

\section{CSC differences based on degree of urbanization}

Table 6 presents standardized estimates of the parameters of the second-order factor model, for the entire data sample and separately for the three observed cities. In the standardized solution, the variances of all latent and manifest variables are fixed to one. Therefore, the standardized regression weights provide information on how strongly the indicator variables correlate with the hypothetical exogenous constructs. The squared value of these weights indicates the explained variance of a manifest variable (indicator's reliability). For example, for the whole sample (All), the construct ENV explains $0.794^{2}=0.6304$ of the variance of the variable Env1 'We buy things if we believe that they can be disposed of in an environmentally friendly manner'. Consequently, a variance of $1-0.6304=0.3696$ remains unexplained. This means that only $37 \%$ of the unit variance of the variable Env1 is due to measurement errors and possibly nonrelevant variable effects. The other values should also be interpreted accordingly. Interpretation of standardized regression weights is straightforward. For example, when ENV goes up by 1 standard deviation, Env1 goes up by 0.794 standard deviations. According to Kline (2015, p. 301) an ideal result in CFA is that the model explains the majority of the variance $(>0.50)$ in every indicator. Hair et al. (2019, p. 694) also provided rules of thumb suggesting that standardized indicator loadings should be at least 0.5 and ideally 0.7 or higher. There are many studies that have reported that factor loadings should be greater than 0.5 for better results (Chen and Tsai, 2007; Truong and McColl, 2011). While exploring pro-environmental consumer behaviour, Ertz, Karakas and Sarigöllü (2016) have considered factor loadings of 0.4 and above for their confirmatory factor analysis. According to later suggestions, our results (with one 
exception, Util $1 \leftarrow$ UTIL for a small city) confirm that the indicators are strongly related to their associated constructs and can be considered as one of the indications of good convergent validity (high factor loadings).

Table 6. Standardized regression weights (default model) in multigroup comparison scenario

\begin{tabular}{|c|c|c|c|c|c|c|}
\hline \multirow[b]{2}{*}{ Consequent } & & \multirow[b]{2}{*}{ Antecedent } & \multicolumn{4}{|c|}{ Standardized Estimates* } \\
\hline & & & All & Sofia (Capital city) & Varna (Large city) & Svishtov (Small city) \\
\hline & & & $\mathrm{n}=1049$ & $\mathrm{n}=403$ & $\mathrm{n}=342$ & $\mathrm{n}=304$ \\
\hline DEBT & $\leftarrow$ & ECON & 0.711 & 0.704 & 0.660 & 0.792 \\
\hline SPAR & $\leftarrow$ & ECON & 0.883 & 0.866 & 0.885 & 0.949 \\
\hline UTIL & $\leftarrow$ & ECON & 0.846 & 0.813 & 0.856 & 0.721 \\
\hline Env1 & $\leftarrow$ & ENV & 0.794 & 0.734 & 0.786 & 0.882 \\
\hline Env2 & $\leftarrow$ & ENV & 0.820 & 0.771 & 0.856 & 0.817 \\
\hline Env3 & $\leftarrow$ & ENV & 0.801 & 0.810 & 0.864 & 0.704 \\
\hline Env4 & $\leftarrow$ & ENV & 0.799 & 0.811 & 0.813 & 0.788 \\
\hline Env5 & $\leftarrow$ & ENV & 0.747 & 0.761 & 0.717 & $0 ., 758$ \\
\hline Debt4 & $\leftarrow$ & DEBT & 0.690 & 0.653 & 0.708 & 0.697 \\
\hline Debt3 & $\leftarrow$ & DEBT & 0.800 & 0.805 & 0.804 & 0.780 \\
\hline Debt2 & $\leftarrow$ & DEBT & 0.897 & 0.869 & 0.939 & 0.880 \\
\hline Debt1 & $\leftarrow$ & DEBT & 0.722 & 0.747 & 0.765 & 0.576 \\
\hline Soc1 & $\leftarrow$ & SOC & 0.925 & 0.915 & 0.942 & 0.906 \\
\hline Soc2 & $\leftarrow$ & SOC & 0.872 & 0.874 & 0.872 & 0.860 \\
\hline Soc3 & $\leftarrow$ & SOC & 0.935 & 0.927 & 0.946 & 0.926 \\
\hline Spar1 & $\leftarrow$ & SPAR & 0.704 & 0.749 & 0.677 & 0.723 \\
\hline Spar2 & $\leftarrow$ & SPAR & 0.708 & 0.723 & 0.700 & 0.709 \\
\hline Spar3 & $\leftarrow$ & SPAR & 0.704 & 0.749 & 0.694 & 0.517 \\
\hline Util1 & $\leftarrow$ & UTIL & 0.677 & 0.771 & 0.760 & $\underline{0.377}$ \\
\hline Util2 & $\leftarrow$ & UTIL & 0.797 & 0.693 & 0.836 & 0.958 \\
\hline
\end{tabular}

* All estimates are significantly different from zero at the 0.001 level (two-tailed).

Source: Authors' own research

We have conducted a multigroup analysis, where the groups are different at the model level. To check if there are statistically significant differences in the estimated regression weights among observed urban areas, we have conducted Chi-square difference test between our unconstrained multigroup model and constrained one (i.e., a model in which the regression measurement weights are constrained to be equal to each other). The test result (Table 7) confirmed our preliminary hypothesis that there were statistically significant differences in effect sizes between at least two of the three compared cities. Therefore, observed groups are significantly different at the model level.

Table 7. Chi-square difference test in multigroup comparison scenario

\begin{tabular}{lrrr}
\hline & Chi-square & df & p-value \\
\cline { 2 - 4 } Overall Model & & \\
Unconstrained & 1005.253 & 416 \\
Fully constrained & 1081.916 & 458 \\
Number of groups & & 3 & 0.001 \\
\cline { 3 - 4 } & & 76.663 & \multicolumn{1}{c}{ Source: Authors' own research }
\end{tabular}

The results demand for checking and comparing path differences between cities in multigroup comparison scenario. We have calculated the differences between the estimates of regression weights and their standard errors and confidence intervals to determinate if they are significant at 95\% confidence level. Using the critical ratios for 
each pair of parameter estimates, we have conducted a test of the hypothesis that the two parameters are equal (Gaskin, 2016).

Differences in consciousness for sustainable consumption orientation across households living in different-sized urban areas has been presented in Table 8. As we can recognize, there are significant differences in the estimates of regression weights SPAR $\leftarrow$ ECON $(\mathrm{p}<0.05)$, Debt3 $\leftarrow$ DEBT $(\mathrm{p}<0.01)$ and Util $1 \leftarrow$ UTIL $(\mathrm{p}<0.05)$ between the capital city and large city; Env3 $\leftarrow$ ENV $(\mathrm{p}<0.01)$, Env5 $\leftarrow$ ENV $(\mathrm{p}<0.05)$, Debt $3 \leftarrow$ DEBT $(\mathrm{p}<0.01)$, Debt $2 \leftarrow$ DEBT $(\mathrm{p}<0.05)$, Debt $1 \leftarrow$ DEBT $(\mathrm{p}<0.01)$, Spar3 $\leftarrow$ SPAR $(\mathrm{p}<0.01)$ and Util1 $\leftarrow$ UTIL $(\mathrm{p}<0.01)$ between the capital city and small city; Env2 $\leftarrow$ ENV ( $\mathrm{p}<0.01)$, Env3 $\leftarrow$ ENV $(\mathrm{p}<0.01)$, Env4 $\leftarrow$ ENV $(\mathrm{p}<0.05)$, Debt1 $\leftarrow$ DEBT $(\mathrm{p}<0.05)$, Spar3 $\leftarrow$ SPAR $(\mathrm{p}<0.05)$ and Util1 $\leftarrow$ UTIL $(\mathrm{p}<0.01)$ between the large and small city.

Table 8. Differences in Consciousness for Sustainable Consumption Orientation across households living in different-sized urban area

\begin{tabular}{|c|c|c|c|c|c|c|c|c|c|c|c|c|c|c|}
\hline & & & \multicolumn{4}{|c|}{ Sofia vs. Varna } & \multicolumn{4}{|c|}{ Sofia vs. Svishtov } & \multicolumn{4}{|c|}{ Varna vs. Svishtov } \\
\hline & & & Estimate & Estimate & z-score & $\mathrm{p}$-value & Estimate & Estimate & z-score & p-value & Estimate & Estimate & z-score & p-value \\
\hline DEBT & $\leftarrow$ & ECON & 0.837 & 0.68 & -1.149 & 0.125 & 0.837 & 0.895 & 0.380 & 0.648 & 0.680 & 0.895 & 1.581 & 0.943 \\
\hline SPAR & $\leftarrow$ & ECON & 1.198 & 0.879 & -1.786 & $* 0.037$ & 1.198 & 0.975 & -1.226 & 0.110 & 0.879 & 0.975 & 0.638 & 0.738 \\
\hline Env2 & $\leftarrow$ & ENV & 0.966 & 1.118 & 1.595 & 0.945 & 0.966 & 0.851 & -1.383 & 0.083 & 1.118 & 0.851 & -3.183 & ${ }^{* *} 0.001$ \\
\hline Env3 & $\leftarrow$ & ENV & 0.982 & 1.084 & 1.113 & 0.867 & 0.982 & 0.741 & -2.849 & ** 0.002 & 1.084 & 0.741 & -4.051 & ${ }^{* *} 0.000$ \\
\hline Env4 & $\leftarrow$ & ENV & 0.998 & 1.051 & 0.569 & 0.715 & 0.998 & 0.864 & -1.572 & 0.058 & 1.051 & 0.864 & -2.195 & ${ }^{*} 0.014$ \\
\hline Env5 & $\leftarrow$ & ENV & 1.055 & 0.974 & -0.798 & 0.212 & 1.055 & 0.862 & -2.078 & *0.019 & 0.974 & 0.862 & -1.251 & 0.105 \\
\hline Debt3 & $\leftarrow$ & DEBT & 1.336 & 0.991 & -2.779 & $* * 0.003$ & 1.336 & 0.942 & -3.064 & ${ }^{* *} 0.001$ & 0.991 & 0.942 & -0.467 & 0.320 \\
\hline Debt2 & $\leftarrow$ & DEBT & 1.318 & 1.169 & -1.209 & 0.113 & 1.318 & 1.074 & -1.899 & $* 0.029$ & 1.169 & 1.074 & -0.834 & 0.202 \\
\hline Debt1 & $\leftarrow$ & DEBT & 1.175 & 1.057 & -1.103 & 0.135 & 1.175 & 0.83 & -2.950 & **0.002 & 1.057 & 0.830 & -2.116 & ${ }^{*} 0.017$ \\
\hline Soc2 & $\leftarrow$ & SOC & 0.925 & 0.889 & -0.736 & 0.231 & 0.925 & 0.885 & -0.724 & 0.235 & 0.889 & 0.885 & -0.064 & 0.474 \\
\hline Soc3 & $\leftarrow$ & SOC & 1.018 & 0.983 & -0.765 & 0.222 & 1.018 & 1.025 & 0.121 & 0.548 & 0.983 & 1.025 & 0.801 & 0.788 \\
\hline Spar2 & $\leftarrow$ & SPAR & 0.999 & 1.061 & 0.628 & 0.735 & 0.999 & 1.056 & 0.503 & 0.693 & 1.061 & 1.056 & -0.051 & 0.480 \\
\hline Spar3 & $\leftarrow$ & SPAR & 0.977 & 0.985 & 0.060 & 0.524 & 0.977 & 0.654 & -2.529 & **0.006 & 0.985 & 0.654 & -2.331 & ${ }^{*} 0.010$ \\
\hline Util1 & $\leftarrow$ & UTIL & 1.127 & 0.891 & -1.740 & $* 0.041$ & 1.127 & 0.41 & -4.833 & ** 0.000 & 0.891 & 0.410 & -3.86 & ${ }^{* *} 0.000$ \\
\hline
\end{tabular}

Notes: Significantly different at the level ${ }^{* *} \mathrm{p}$-value $<0.01 ;^{*} \mathrm{p}$-value $<0.05$ (one-tailed).

Source: Authors' own research

\section{Developing a consciousness for sustainable consumption index using structural regression model}

To develop a consciousness for sustainable consumption index at the individual household level, we have built a partially latent structural regression model. It consists of some latent and some observed variables. We have followed best practice using a two-step modelling approach. First, we have developed and confirmed a second-order measurement model, and second, we have composed a structural model using measurement components (Figure 2). CSC index model demonstrates excellent goodness-of-fit (Table 9). 


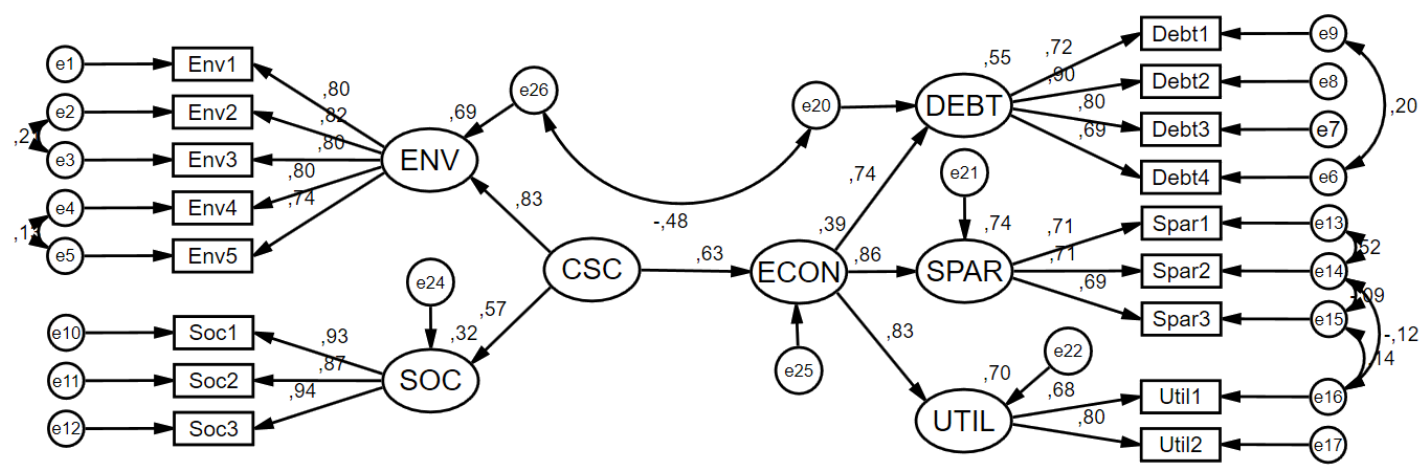

Figure 2. Partially latent structural regression model for CSC Index at individual household level

Source: Authors' own research

Table 9. Goodness-of-fit of CSC Index model

\begin{tabular}{llll}
\hline \multicolumn{2}{l}{ CSC Index Model Fit Measures } & & \\
\hline Measure & Estimate & Threshold & Interpretation \\
CMIN & 272.975 & -- & -- \\
DF & 105 & -- & -- \\
CMIN/DF & 2.600 & Between 1 and 3 & Excellent \\
CFI & 0.984 & $>0.95$ & Excellent \\
SRMR & 0.034 & $<0.08$ & Excellent \\
RMSEA & 0.039 & $<0.06$ & Excellent \\
PClose & 0.999 & $>0.05$ & Excellent \\
\hline
\end{tabular}

Source: Authors' own research

In order to estimate household scores on each latent factor and use it as an observed characteristic (household's index) in different type of analyses, as well as to determine their ranking, we have stored the predicted values after the implantation of the CFA. Because factor scores are essentially the averages of the indicator "weighted" by the strength of the factor loading, they are not identical to the simple averages. To calculate CSC index score for each household in the sample we have imputed weighted average composite variables based on the loadings and error in the second-order CFA model. This is much more accurate than using the simple unweighted averages. We have applied regression imputation procedure (DiStefano et al., 2009), where the model has been first fitted using maximum likelihood. After that, model parameters have been set to be equal to their maximum likelihood estimates. A linear regression has been used to predict the unobserved values for each case as a linear combination of the observed values for that same case. Then, the predicted values have been plugged in for the missing values (Arbuckle, 2020).

The model has allowed us to also calculate the following seven indices: CSC index, ECON index, UTIL index, SPAR index, SOC index, DEBT index, and ENV index. Also, the analysis has been performed using the databases for each of the cities and by aggregating the overall database. As all latent variables CSC, ECON, UTIL, SPAR, SOC, DEBT, ENV are factor scores, which have been generated as a result of the multigroup analysis, we have rescaled them to bring their values in the range from 0 to $100 \mathrm{using}$ unity-based normalisation procedure.

Table 10 includes the mean values of the seven indices generated from the CSC Index model using the overall database of 1049 cases. It is interesting to test if there are any significant differences in the level of the CSC Index between the capital city, large and small city, as well as regarding households' socio-demographic characteristics. We have used One-way ANOVA procedure. We could not identify any significant differences in the level of the CSC Index regarding the size of the city, age of the head of the 
household, size of the household, ownership of the main housing unit occupied by the household, type of the primary residence of the household, and the living area of the primary residence of the household. The first significant difference in the level of the CSC Index we have managed to identify is regarding the gender of the head of the household $(F=5.525$, Sig. $=0.034<0.05)$. CSC Index is significantly higher for women than for men. (0.5399>0.5149).

Another interesting and significant difference in the levels of the CSC Index has been identified regarding the household's waste sorting behaviour (Yes=347 and No=702; F=123.640, Sig. $=0.000<0.01$ ). As expected, the average value of the CSC Index for those households who sort waste is higher than for those who do not sort waste $(0.6036>0.4825)$.

Table 10. Descriptive statistics of the variables in the CSC Index model for the overall database

\begin{tabular}{lrrrr}
\hline & $\mathrm{N}$ & Minimum & Maximum & \multicolumn{1}{c}{ Mean } \\
\cline { 2 - 6 } CSCIndex & $\mathbf{1 0 4 9}$ & $\underline{\mathbf{0 0}}$ & $\underline{\mathbf{1 . 0 0}}$ & $\mathbf{. 6 2 2 6}$ \\
ECONIndex & $\mathbf{1 0 4 9}$ & .00 & 1.00 & $\mathbf{. 6 4 8 6}$ \\
UTILIndex & 1049 & .00 & 1.00 & .6624 \\
SPARIndex & 1049 & $\mathbf{. 0 0}$ & $\mathbf{1 . 0 0}$ & .6280 \\
SOCIndex & $\mathbf{1 0 4 9}$ & .00 & 1.00 & .7286 \\
DEBTIndex & 1049 & $\mathbf{. 0 0}$ & $\mathbf{1 . 0 0}$ & $\mathbf{. 4 7 8 8}$ \\
ENVIndex & $\mathbf{1 0 4 9}$ & & & \\
\hline Valid N (listwise) & 1049 & & &
\end{tabular}

Source: Authors' own research

As one of our objectives was to identify heterogeneity between consumers in regards to their stated willingness to comply with the principles of sustainable consumption, we have applied Ward's hierarchical agglomerative clustering method. The clustering has been conducted in two ways: (1) by using as inputs only the data regarding households' stated willingness to comply with the principles of sustainable consumption (i.e., ECON index, SOC index and ENV Index); (2) by adding sociodemographics of the households to the dataset in (1). The dendrogram that was constructed using the Ward's linkage approach suggests the presence of two distinctive clusters. We have achieved a similar result by applying a two-step clustering method (Table 11), which confirms the existence of two segments 'Sustainable conscious' $(42.2 \%)$ versus 'Sustainable unconscious' (57.8\%).

We have repeated the cluster analysis by adding socio-demographic variables of the households and city size to the three indices of sustainable consumption. The results of the extended segmentation confirm the existence and proportion of the two abovementioned segments 'Sustainable conscious' and 'Sustainable unconscious'. In comparison with sustainable unconscious households (Table 11), sustainable conscious households have higher levels of socially fair $(0.44<0.80)$, economically reasonable $(0.57<0.76)$ and environmentally friendly consumption $(0.36<0.63)$.

Figure 3 illustrates the relative importance of predictors (varying from 0.0 (least important) to 1.00 (most important)) that have been used as inputs of the extended two-step clustering. Socially fair consumption is considered as the most significant predictor with the strongest impact. Waste sorting and the three indices ECON Index, SOC Index and ENV Index are the only significant predictors of the cluster membership. Neither socio-demographic characteristics, nor the size of the cities contribute for the differentiation between sustainable conscious and sustainable unconscious households. 
Table 11. Two-step clustering of households on the basis of their stated willingness to comply with the principles of sustainable consumption

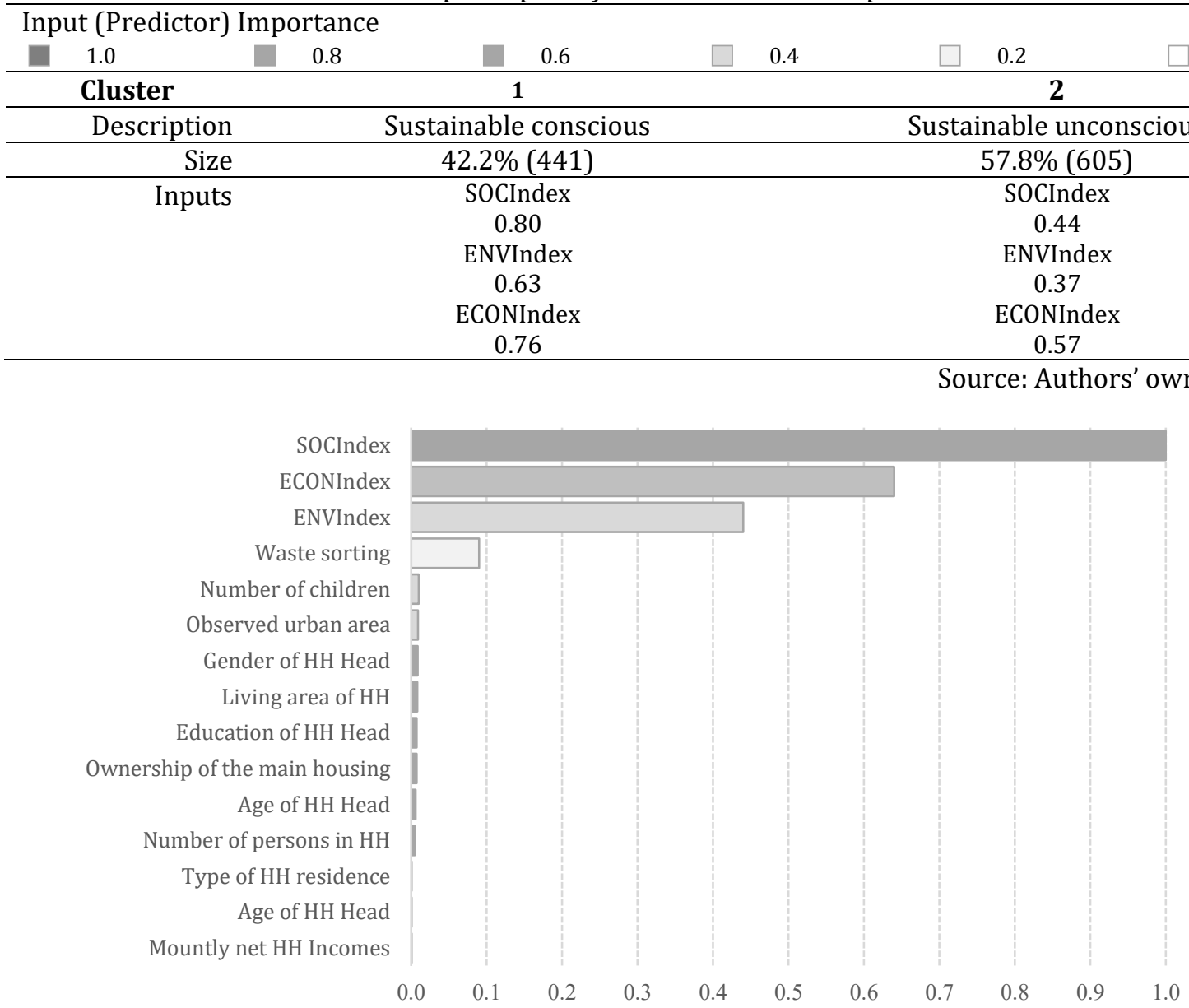

Figure 3. Predictor importance

Source: Authors' own research

\section{Relative importance of the sustainable index dimensions}

Following the Crohn's method-based approach (Croon, 2002), suggested by Devlieger and Rosseel (2017, p. 32) and Kelcey et al. (2021, p. 4), we have used the measurement models to perform a factor analysis for each latent variable ENV Index, SOC Index, and ECON Index separately, and then we have calculated their factor scores. We have created a path model (Figure 5) and performed a classical factor score path analysis using AMOS.

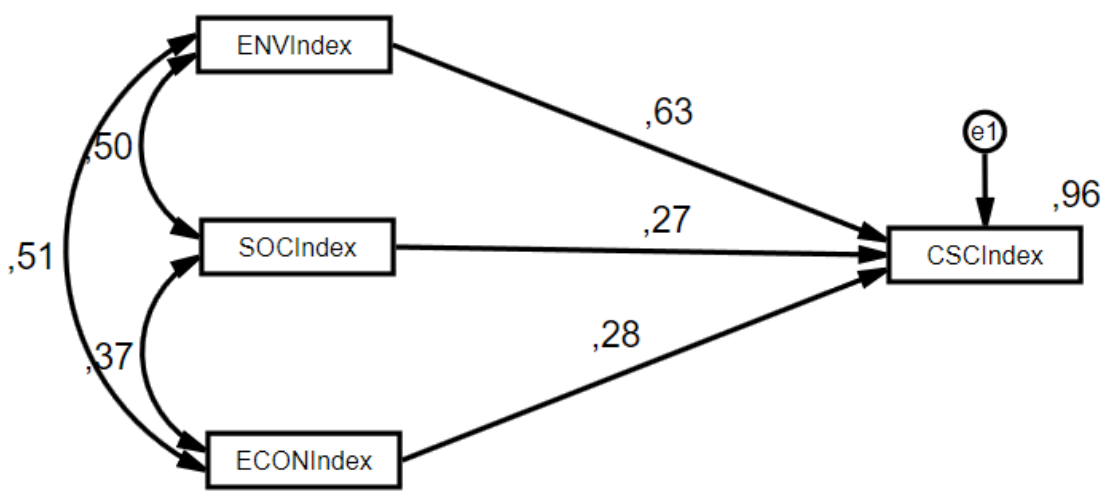

Figure 5. Path model of CSC Index 
The model has an exceptional goodness-of-fit $\left(R^{2}=0.96\right)$. Regression and correlations coefficients of the model are presented in Table 12.

Table 12. Regression and correlation coefficients of the path model (entire data sample) (All - Default model)

\begin{tabular}{llll}
\hline \multicolumn{2}{l}{ Standardized Regression Weights } & Estimate \\
\hline CSCIndex & $\leftarrow$ & ECONIndex & $0.285^{* *}$ \\
CSCIndex & $\leftarrow$ & ENVIndex & $0.633^{* *}$ \\
CSCIndex & $\leftarrow$ & SOCIndex & $0.268^{* *}$ \\
\hline \multicolumn{2}{r}{ Notes: Significantly at the level ${ }^{* *}$ p-value $<0.01 ;$ (two-tailed). }
\end{tabular}

\begin{tabular}{llll}
\hline Correlations & & & Estimate \\
\hline ENVIndex & $\leftrightarrow$ & SOCIndex & $0.501^{* *}$ \\
ECONIndex & $\leftrightarrow$ & SOCIndex & $0.374^{* *}$ \\
ECONIndex & $\leftrightarrow$ & ENVIndex & $0.514^{* *}$ \\
\hline
\end{tabular}

Source: Authors' own research

The values of the standardized regression coefficients, calculated on the basis of the entire data sample, suggest that the ENV Index has the strongest impact on the CSC Index, which is more than 2.5 times stronger than the effects of the SOC Index and ECON Index (Table 12, left part). At the same time, there is a relatively high correlation between all dimensions of the CSCs Index (Table 12, right part), which means that the economic and ecological dimensions, as well as the ecological and social dimensions are strongly interrelated. The association between the economic and social dimensions is weaker than the other two above-mentioned associations.

The multigroup comparisons between the capital city, large and small city confirm our conclusions (Table 13) that the environmental dimension is the most significant predictor of the consciousness for sustainable consumption.

Table 13. Regression and correlation coefficients of the path model in multigroup comparison scenario

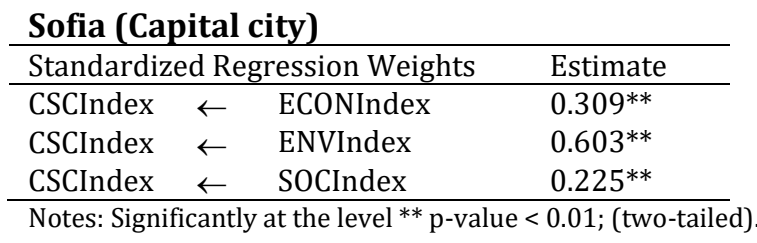

\begin{tabular}{llll}
\hline Correlations & & & Estimate \\
\hline ENVIndex & $\leftrightarrow$ & SOCIndex & $0.603^{* *}$ \\
ECONIndex & $\leftrightarrow$ & SOCIndex & $0.508^{* *}$ \\
ECONIndex & $\leftrightarrow$ & ENVIndex & $0.659^{* *}$ \\
\hline
\end{tabular}

Varna (Large city)

\begin{tabular}{llll}
\hline \multicolumn{2}{l}{ Standardized Regression Weights } & Estimate \\
\hline CSCIndex $\leftarrow$ & ECONIndex & $0.304^{* *}$ \\
CSCIndex $\leftarrow \quad$ ENVIndex & $0.699^{* *}$ \\
CSCIndex $\leftarrow \quad$ SOCIndex & $0.130^{* *}$ \\
\hline Notes: Significantly at the level ${ }^{* *}$ p-value $<0.01$; (two-tailed).
\end{tabular}

\begin{tabular}{llll}
\hline Correlations & & & Estimate \\
\hline ENVIndex & $\leftrightarrow$ & SOCIndex & $0.470^{* *}$ \\
ECONIndex & $\leftrightarrow$ & SOCIndex & $0.366^{* *}$ \\
ECONIndex & $\leftrightarrow$ & ENVIndex & $0.630^{* *}$ \\
\hline
\end{tabular}

Svishtov (Small city)

\begin{tabular}{llll}
\hline \multicolumn{2}{l}{ Standardized Regression Weights } & Estimate \\
\hline CSCIndex $\leftarrow$ & ECONIndex & $0.199^{* *}$ \\
CSCIndex $\leftarrow \quad$ ENVIndex & $0.604^{* *}$ \\
CSCIndex $\leftarrow \quad$ SOCIndex & $0.483^{* *}$ \\
\hline Notes: Significantly at the level & ** p-value $<$ & 0.01 ; (two-tailed).
\end{tabular}

\begin{tabular}{llll}
\hline Correlations & & & Estimate \\
\hline ENVIndex & $\leftrightarrow$ & SOCIndex & $0.425^{* *}$ \\
ECONIndex & $\leftrightarrow$ & SOCIndex & $0.208^{* *}$ \\
ECONIndex & $\leftrightarrow$ & ENVIndex & $0.228^{* *}$ \\
\hline
\end{tabular}

Source: Authors' own research

No matter the size of the city, the environmental dimension has the strongest effect on the consciousness for sustainable consumption. It is interesting to recognise that the social dimension has approximately 2.0 times stronger effect on the consciousness for sustainable consumption in the small city in comparison with the capital and large city. The multigroup analysis also reveals that the ecological and social dimensions are interrelated in a strongest way for the capital city. 


\section{Discussion}

In this paper, we have verified and extended the CSC model designed by Balderjahn et al. (2013a; 2018a; 2013). We have proposed a second-order factor model, which includes five first-order factors (environmentally friendly consumption, debt-free consumption, socially fair consumption, sparing consumption, and utilitarian consumption) and one second-order factor (economically reasonable consumption, which is comprised by three of the above-mentioned first-order factors - debt-free consumption, sparing consumption, and utilitarian consumption). Using this model and by applying multigroup analysis, we have identified some significant differences in consciousness for sustainable consumption orientation across household groups living in different-sized urban areas.

More specifically, we have developed and proposed a CSC Index model at the individual household level using a partially latent structural regression model. The model includes seven sub-indices, which represent the dimensions of the consciousness for sustainable consumption. After applying a unity-based normalization to the values of all indices and one-way ANOVA procedure, we have not managed to identify any significant differences in the level of the CSC Index regarding the size of the city, age of the head of the household, size of the household, ownership of the main housing unit occupied by the household, type of the primary residence of the household, and the living area of the primary residence of the household. However, we found two significant differences: (1) CSC Index is significantly higher for women, who recognized themselves as the head of the household, than for men, and (2) CSC Index is significantly higher in households who sort waste than those who do not sort waste.

As one of our objectives was to check if the households in different-sized urban settings differ in their sustainable consumer behaviour, we have conducted both twostep clustering method and Ward's hierarchical agglomerative clustering method. We have identified two distinctive segments 'Sustainable conscious' versus 'Sustainable unconscious'. We have found that only socially fair consumption, followed by environmentally friendly consumption and economically reasonable consumption, as well as waste sorting are predictors of the cluster membership. Neither sociodemographic characteristics, nor the size of the cities contribute for the differentiation between sustainable conscious and sustainable unconscious households.

We have also designed and evaluated a path model of the CSC Index to identify the relative importance of the dimensions of the consciousness for sustainable consumption. Using this model, we found that, no matter the size of the city, the environmental dimension has the strongest effect on the consciousness for sustainable consumption.

To our knowledge, no similar empirical results have been reported in recent years. We consider the problem to be important, especially in the context of the increasing concentration of urban populations towards large cities and the capital and the resulting depopulation of small towns. In this context, the findings could be used as a recommendation for the development of municipal strategies to launch a wastesorting campaign regardless of the level of urbanisation. In addition, companies operating in local urban markets should take these specificities into account and define an appropriate regional marketing strategy whose communication component focuses on segment specificities.

The results and conclusions of this study are subject to limitations. First, our sample is not representative of the population of Bulgaria as a whole. Our sample included respondents from the capital, a typical large city and a typical small city. 
Accordingly, we cannot make valid statements about household consumption by rural areas as a whole, but at best for the part of the population whose profiles are covered by this study. On the other hand, practical marketing requires representative data. For the development of scales and indicators, however, too heterogeneous data are not always well suited. However, we consider the CSC Index construction methodology robust enough to be applied to larger samples.

\section{Acknowledgement}

This research is funded by the National Science Fund of Bulgaria (BNSF) under the project No. КП-06-H35/7 from 12/2019.

\section{Data}

The data used for the analysis in this paper can be accessed at: https://bit.ly/3h8n9xY

\section{References}

Anderson, W.T. and Cunningham, W.H. (1972), "The Socially Conscious Consumer", Journal of Marketing, American Marketing Association, Vol. 36 No. 3, pp. 23-31.

Antil, J.H. (1984), "Socially Responsible Consumers: Profile and Implications for Public Policy", Journal of Macromarketing, Vol. 4 No. 2, available at: https://doi.org/10.1177/027614678400400203.

Antil, J.H. and Bennett, P.D. (1979), "Construction and Validation of a Scale to Measure Socially Responsible Consumption Behavior", in Henion II, K.E. and Kinnear, C. (Eds.), The Conserver Society, American Marketing Association, Chicago, pp. 5169.

Arbuckle, J.L. (2020), “IBM SPSS Amos (Version 27.0)”, IBM SPSS, Armonk, NY, available at: https://www.ibm.com/products/structural-equation-modeling-sem (accessed 8 May 2021).

Badenes-Ribera, L., Silver, N.C. and Pedroli, E. (2020), “Editorial: Scale Development and Score Validation", Frontiers in Psychology, available at: https://doi.org/10.3389/fpsyg.2020.00799.

Balderjahn, I., Buerke, A., Kirchgeorg, M., Peyer, M., Seegebarth, B. and Wiedmann, K.-P. (2013a), "Consciousness for sustainable consumption: scale development and new insights in the economic dimension of consumers' sustainability", AMS Review, available at: https://doi.org/10.1007/s13162-013-0057-6.

Balderjahn, I., Buerke, A., Kirchgeorg, M., Peyer, M., Seegebarth, B. and Wiedmann, K.-P. (2013b), "Consciousness for sustainable consumption: scale development and new insights in the economic dimension of consumers' sustainability", $A M S$ Review.

Balderjahn, I. and Hüttel, A. (2019a), "Why consumers buy sustainably: The role of personal values", Marketing, Zeitschrift Fur Forschung Und Praxis, C. H. BECK oHG, Vol. 41 No. 1, pp. 24-38.

Balderjahn, I. and Hüttel, A. (2019b), "Why consumers buy sustainably: The role of personal values", Marketing, Zeitschrift Fur Forschung Und Praxis, Vol. 41 No. 1, pp. 24-38.

Balderjahn, I., Lee, M.S.W., Seegebarth, B. and Peyer, M. (2019), “A Sustainable Pathway to Consumer Wellbeing. The Role of Anticonsumption and Consumer Empowerment", Journal of Consumer Affairs, available at: https://doi.org/10.1111/joca.12278. 
Balderjahn, I. and Peyer, M. (2012), "Das Bewusstsein für fairen Konsum :

Konzeptualisierung, Messung und Wirkung”, Die Betriebswirtschaft : DBW.

Balderjahn, I., Peyer, M. and Paulssen, M. (2013), “Consciousness for fair consumption: Conceptualization, scale development and empirical validation", International Journal of Consumer Studies.

Balderjahn, I., Peyer, M., Seegebarth, B., Wiedmann, K.P. and Weber, A. (2018a), "The many faces of sustainability-conscious consumers: A category-independent typology", Journal of Business Research, Elsevier Inc., Vol. 91, pp. 83-93.

Balderjahn, I., Peyer, M., Seegebarth, B., Wiedmann, K.-P. and Weber, A. (2018b), "The many faces of sustainability-conscious consumers", Journal of Business Research Journal, Vol. 91, pp. 83-93.

Barrett, P. (2007), "Structural equation modelling: Adjudging model fit", Personality and Individual Differences, Vol. 42 No. 5, available at: https://doi.org/10.1016/j.paid.2006.09.018.

Bentler, P.M. and Chou, C.P. (1987), "Practical Issues in Structural Modeling”, Sociological Methods \& Research, Vol. 16 No. 1, available at:https://doi.org/10.1177/0049124187016001004.

Braeken, J. and van Assen, M.A.L.M. (2017), “An empirical Kaiser criterion.”, Psychological Methods, Vol. 22 No. 3, available at: https://doi.org/10.1037/met0000074.

Browne, M.W. and Cudeck, R. (1992), "Alternative Ways of Assessing Model Fit", Sociological Methods \& Research, Vol. 21 No. 2, available at: https://doi.org/10.1177/0049124192021002005.

Brown, T. (2015), Confirmatory Factor Analysis for Applied Research, Second Edition, Guilford Publications.

Byrne, B.M. (2016), Structural Equation Modeling with AMOS: Basic Concepts, Applications, and Programming, Structural Equation Modeling with AMOS: Basic Concepts, Applications, and Programming, Second Edition, 3rd ed., Routledge, New York.

Chen, C.F. and Tsai, D.C. (2007), "How destination image and evaluative factors affect behavioral intentions?", Tourism Management, Vol. 28 No. 4, available at: https://doi.org/10.1016/j.tourman.2006.07.007.

Croon, M. (2002), "Using Predicted Latent Scores in General Latent Structure Models", in Marcoulides, G.A. and Moustaki, I. (Eds.), Latent Variable and Latent Structure Models, Lawrence Erlbaum Associates, Mahwahl, NJ, pp. 195-224.

Devlieger, I. and Rosseel, Y. (2017), "Factor Score Path Analysis", Methodology, Hogrefe Publishing Group, Vol. 13 No. Supplement 1, pp. 31-38.

Diaconis, P. and Efron, B. (1983), “COMPUTER-INTENSIVE METHODS IN STATISTICS.”, Scientific American, Vol. 248 No. 5, available at: https://doi.org/10.1038/scientificamerican0583-116.

DiStefano, C., Zhu, M. and Mîndrilă, D. (2009), "Understanding and using factor scores: Considerations for the applied researcher", Practical Assessment, Research and Evaluation, Vol. 14 No. 20.

Efron, B. (1982), The Jackknife, the Bootstrap and Other Resampling Plans, The Jackknife, the Bootstrap and Other Resampling Plans, Society for Industrial and Applied Mathematics, Philadelphia, available at: https://doi.org/10.1137/1.9781611970319.

Enders, C.K. (2002), "Applying the Bollen-Stine bootstrap for goodness-of-fit measures to structural equation models with missing data", Multivariate Behavioral 
Research, Vol. 37 No. 3, available at:

https://doi.org/10.1207/S15327906MBR3703_3.

Ertz, M., Karakas, F. and Sarigöllü, E. (2016), "Exploring pro-environmental behaviors of consumers: An analysis of contextual factors, attitude, and behaviors", Journal of Business Research, Vol. 69 No. 10, available at: https://doi.org/10.1016/j.jbusres.2016.06.010.

Fisk, G. (1973), "Criteria for a Theory of Responsible Consumption", Journal of Marketing, Vol. 37 No. 2, available at: https://doi.org/10.1177/002224297303700206.

Follows, S.B. and Jobber, D. (2000), "Environmentally responsible purchase behaviour: a test of a consumer model”, European Journal of Marketing, Vol. 34 No. 5/6, available at: https://doi.org/10.1108/03090560010322009.

Fornell, C. and Larcker, D.F. (1981), "Evaluating Structural Equation Models with Unobservable Variables and Measurement Error", Journal of Marketing Research, Vol. 18 No. 1, available at: https://doi.org/10.2307/3151312.

Francois-Lecompte, A. and Roberts, J. a. (2006), "Developing a Measure of Socially Responsible Consumption in France.", Marketing Management Journal, Vol. 16 No. 2.

Gaskin, J. (2016), “'Name of tab', Stats Tools Package”, http://statwiki.kolobkreations.com.

Gaskin, J., James, M. and Lim, J. (2019), “'Master Validity Tool', AMOS Plugin”, Gaskination's StatWiki, 12 May, available at: http://statwiki.gaskination.com/index.php?title=Plugins (accessed 12 May 2021).

Gaskin, J. and Lim, J. (2016), “'Model Fit Measures', AMOS Plugin”, Gaskination's StatWiki, 12 May, available at: http://statwiki.gaskination.com/index.php?title=Plugins (accessed 12 May 2021).

Ghasemy, M., Teeroovengadum, V., Becker, J.M. and Ringle, C.M. (2020), “This fast car can move faster: a review of PLS-SEM application in higher education research", Higher Education, available at: https://doi.org/10.1007/s10734-020-00534-1.

Gorostiaga, A., Aliri, J., Ulacia, I., Soroa, G., Balluerka, N., Aritzeta, A. and Muela, A. (2019), "Assessment of entrepreneurial orientation in vocational training students: Development of a new scale and relationships with self-efficacy and personal initiative", Frontiers in Psychology, Vol. 10 No. MAY, available at: https://doi.org/10.3389/fpsyg.2019.01125.

Gupta, K. and Singh, N. (2020), Consumption Behaviour and Social Responsibility, Springer, Singapore, available at: http://link.springer.com/10.1007/978-98115-3005-0.

Ha-Brookshire, J.E. and Hodges, N.N. (2009), "Socially responsible consumer behavior?: Exploring used clothing donation behavior", Clothing and Textiles Research Journal, Vol. 27 No. 3, available at: https://doi.org/10.1177/0887302X08327199.

Hair, J.F., Black, W.C., Babin, B.J. and Anderson, R.E. (2019), Multivariate Data Analysis, Annabel Ainscow, 8th ed., Cengage, Andover, UK.

Hair, J.F., Sarstedt, M. and Ringle, C.M. (2019), "Rethinking some of the rethinking of partial least squares", European Journal of Marketing, Vol. 53 No. 4, available at: https://doi.org/10.1108/EJM-10-2018-0665. 
Henseler, J., Ringle, C.M. and Sarstedt, M. (2015), "A new criterion for assessing discriminant validity in variance-based structural equation modeling", Journal of the Academy of Marketing Science, Vol. 43 No. 1, available at: https://doi.org/10.1007/s11747-014-0403-8.

Homburg, Ch. and Giering, A. (1996), "Konzeptualisierung und Operationalisierung komplexer Konstrukte. Ein Leitfaden für die Marketingforschung”, Marketing ZFP, Vol. 18 No. 1, available at: https://doi.org/10.15358/0344-1369-1996-1-5.

Hu, L.T. and Bentler, P.M. (1999), "Cutoff criteria for fit indexes in covariance structure analysis: Conventional criteria versus new alternatives", Structural Equation Modeling, Vol. 6 No. 1, available at: https://doi.org/10.1080/10705519909540118.

IBM Corporation. (n.d.). "IBM SPSS Missing Values”, IBM Corporation, Armonk, NY, available at:

ftp://public.dhe.ibm.com/software/analytics/spss/documentation/statistics/26 .0/en/client/Manuals/IBM_SPSS_Missing_Values.pdf (accessed 7 May 2021).

Kaiser, F.G., Ranney, M., Hartig, T. and Bowler, P.A. (1999), "Ecological Behavior, Environmental Attitude, and Feelings of Responsibility for the Environment", European Psychologist, Vol. 4 No. 2, available at: https://doi.org/10.1027//10169040.4.2.59.

Kaiser, F.G., Wölfing, S. and Fuhrer, U. (1999), "Environmental attitude and ecological behaviour", Journal of Environmental Psychology, Vol. 19 No. 1, pp. 1-19.

Kaiser, H.F. (1960), "The Application of Electronic Computers to Factor Analysis", Educational and Psychological Measurement, Vol. 20 No. 1, available at: https://doi.org/10.1177/001316446002000116.

Kelcey, B., Cox, K. and Dong, N. (2021), “Croon's Bias-Corrected Factor Score Path Analysis for Small- to Moderate-Sample Multilevel Structural Equation Models", Organizational Research Methods, Vol. 24 No. 1, available at: https://doi.org/10.1177/1094428119879758.

Kim, H. and Millsap, R. (2014), "Using the Bollen-Stine Bootstrapping Method for Evaluating Approximate Fit Indices", Multivariate Behavioral Research, Vol. 49 No. 6, available at: https://doi.org/10.1080/00273171.2014.947352.

Kırcova, İ., Enginkaya, E. and Gizem Köse, Ş. (2016), Exploring Turkish Consumers' Socially Responsible Consumption Behavior, AICSS, İstanbul, Türkiye.

Kline, R.B. (2015), Principles and Practices of Structural Equation Modelling, Methodology in the Social Sciences, 4th ed., The Guilford Press, New York.

Korkmaz, S., Goksuluk, D. and Zararsiz, G. (2014), "MVN: An R package for assessing multivariate normality", R Journal, Vol. 6 No. 2, available at: https://doi.org/10.32614/rj-2014-031.

Little, R.J.A. (1988), "A test of missing completely at random for multivariate data with missing values", Journal of the American Statistical Association, Vol. 83 No. 404, available at: https://doi.org/10.1080/01621459.1988.10478722.

Nikolaou, I.E. and Kazantzidis, L. (2016), "A sustainable consumption index/label to reduce information asymmetry among consumers and producers", Sustainable Production and Consumption, Elsevier, Vol. 6, pp. 51-61.

Nunnally, J.C. and Bernstein, I.H. (1994), Psychometric Theory, McGraw-Hill, New York, 3rd ed., Vol. 3, McGraw-Hill, New York.

Pérez-Barea, J.J., Fernández-Navarro, F., Montero-Simó, M.J. and Araque-Padilla, R. (2018), "A socially responsible consumption index based on non-linear 
dimensionality reduction and global sensitivity analysis", Applied Soft Computing Journal, Elsevier Ltd, Vol. 69, pp. 599-609.

Quoquab, F., Mohammad, J. and Sukari, N.N. (2019), “A multiple-item scale for measuring 'sustainable consumption behaviour' construct: Development and psychometric evaluation", Asia Pacific Journal of Marketing and Logistics, Vol. 31 No. 4, available at: https://doi.org/10.1108/APJML-02-2018-0047.

Ramlall, I. (2017), Applied Structural Equation Modelling for Researchers and Practitioners, Applied Structural Equation Modelling for Researchers and Practitioners, Emerald, available at: https://doi.org/10.1108/9781786358820.

Roberts, J.A. (1995), "Profiling Levels of Socially Responsible Consumer Behavior: A Cluster Analytic Approach and Its Implications for Marketing", Journal of Marketing Theory and Practice, Vol. 3 No. 4, available at: https://doi.org/10.1080/10696679.1995.11501709.

Roberts, J.A. and Bacon, D.R. (1997), "Exploring the Subtle Relationships between Environmental Concern and Ecologically Conscious Consumer Behavior", Journal of Business Research, Vol. 40 No. 1, available at: https://doi.org/10.1016/S01482963(96)00280-9.

Schwepker, C.H. and Cornwell, T.B. (1991), "An Examination of Ecologically Concerned Consumers and Their Intention to Purchase Ecologically Packaged Products", Journal of Public Policy \& Marketing, Vol. 10 No. 2, available at: https://doi.org/10.1177/074391569101000205.

Sheth, J.N., Sethia, N.K. and Srinivas, S. (2011), "Mindful consumption: A customercentric approach to sustainability", Journal of the Academy of Marketing Science, Springer Science and Business Media, LLC, Vol. 39 No. 1, pp. 21-39.

Soper, D.S. (2021), "A-priori Sample Size Calculator for Structural Equation Models [Software]", Available from Https://Www.Danielsoper.Com/Statcalc, 6 May.

Truong, Y. and McColl, R. (2011), "Intrinsic motivations, self-esteem, and luxury goods consumption", Journal of Retailing and Consumer Services, Vol. 18 No. 6, available at: https://doi.org/10.1016/j.jretconser.2011.08.004.

Webb, D.J., Mohr, L.A. and Harris, K.E. (2008), “A re-examination of socially responsible consumption and its measurement", Journal of Business Research, Vol. 61 No. 2, available at: https://doi.org/10.1016/j.jbusres.2007.05.007.

Webster, F.E. (1975), "Determining the Characteristics of the Socially Conscious Consumer", Journal of Consumer Research, Oxford University Press, Vol. 2 No. 3, pp. 188-196.

Wolf, E.J., Harrington, K.M., Clark, S.L. and Miller, M.W. (2013), "Sample Size Requirements for Structural Equation Models: An Evaluation of Power, Bias, and Solution Propriety", Educational and Psychological Measurement, Vol. 73 No. 6, available at: https://doi.org/10.1177/0013164413495237.

Yurdugül, H. (2008), “Minimum sample size Cronbach's coefficient alpha: A Monte-Carlo study", Hacettepe Egitim Dergisi, No. 35. 